\title{
Realidade e esforços de cirurgiões-dentistas em Odontologia Comunitária
}

\author{
Murilo Galdino Reis de Souza*; Paula Côrrea Souza*; Rita de Cássia Gabrielli Souza Lima** \\ * Estudante de graduação em Odontologia, Universidade \\ do Vale do Itajaí \\ ** Doutora em Saúde Coletiva, docente e pesquisadora, \\ Universidade do Vale do Itajaí
}

Recebido em 22/07/2019. Aprovado em 20/06/2020.

\begin{abstract}
RESUMO
Este artigo situa-se no contexto da Estratégia Saúde da Família (ESF) de um município catarinense de grande porte. Objetiva-se discutir aspectos da realidade do processo de trabalho em saúde bucal e do empenho de cirurgiões-dentistas para garantir práticas odontológicas integrais individuais e coletivas aos respectivos territórios de atuação. Caracteriza-se como estudo qualitativo, exploratóriodescritivo, realizado com seis cirurgiões-dentistas por meio de entrevista semiestruturada e análise temática ajustada. Os resultados indicam um descompasso entre o número de equipes de saúde bucal, por população adstrita, ausência de parâmetros regulatórios e de metas para as distintas clínicas de base odontológica, e ausência de alinhamento estrutural entre as práticas desenvolvidas e a realidade sociocultural de cada território. Identificou-se um esforço substantivo do coletivo de profissionais para: a) se apropriar cotidianamente da filosofia da ESF e/ou expandi-la; b) reconhecer que é preciso disposição para apreender a dimensão pública da saúde bucal no ato de fazê-la, pois a graduação nem sempre é suficiente para garantir a apropriação das clínicas de saúde bucal individual e coletiva; c) reconhecer a importância de transformar-se em um intelectual criativo e orgânico, que assume um protagonismo social; e d) superar os efeitos gerados nas práticas por ausência de representação política da saúde bucal da ESF. Considera-se que a garantia de práticas odontológicas integrais está no horizonte, à espera de condições de possibilidades para tornar real o que ainda se encontra no plano de esforços autônomos, do arcabouço institucional e de boas intenções.
\end{abstract}

Descritores: Odontologia Comunitária. Estratégia Saúde da Família. Atenção Básica.

A principal tarefa [..] não é julgar, mas compreender [...]. $O$ difícil é compreender.

Eric Hobsbawn 


\section{INTRODUÇÃO}

O projeto em defesa de um sistema nacional de saúde para o Brasil, em execução desde meados da década de 1970 e consagrado em 1988 como Sistema Único de Saúde (SUS), tem como finalidade a transformação das históricas desigualdades sociais de atenção à saúde e doença em igualdade de direitos ${ }^{1}$. Para viabilizá-la, o projeto previu, ainda nos anos 70, um movimento de integração docente assistencial visando à modificação das práticas de ensino ${ }^{2}$.

No início deste milênio, aliaram-se a este projeto as Diretrizes Curriculares Nacionais, criadas pelo Conselho Nacional de Educação para impulsionar a formação para o SUS em cursos de graduação de áreas da saúde ${ }^{3}$. Desde então, as universidades brasileiras têm investido em novas matrizes pedagógicas. Entre as medidas tomadas, cabe citar a inserção da disciplina Saúde Coletiva em projetos pedagógicos ${ }^{4}$, a criação de cursos de Bacharelado em Saúde Coletiva ${ }^{5,6}$ e a expansão de estágios supervisionados nos serviços de atenção básica, em resposta à luta pela transformação das práticas de ensino, iniciadas no movimento de integração docente assistencial, na década de $1970^{2}$.

No entanto, o processo histórico tem revelado que a formação em saúde, no Brasil, continua não orientada maciçamente para o SUS porque ainda não foi deflagrado um amplo e orgânico movimento político-pedagógico para este fim $^{7}$. Desde a década de 1990, a luta em prol do ensino da Saúde Coletiva em cursos de graduação da área da saúde defronta-se com a expansão do projeto neoliberal ${ }^{8}$. Uma razão expoente é o fato de que as universidades brasileiras ainda não superaram a formação especialista $^{7}$, que dialoga com a lógica liberalprivatista.

No âmbito dos serviços, por sua vez, os profissionais atuantes na Estratégia Saúde da Família (ESF) da Atenção Básica (AB) do SUS convivem com a ausência de formação continuada sobre modelos teóricos e de práticas que são criados pelo governo federal para substituir modelos que foram objetos de suas graduações. Geralmente, as mudanças chegam na ponta (nos serviços), para ser executadas de acordo com decretos, portarias, resoluções, medidas provisórias e leis, sem formação simultânea dos trabalhadores ${ }^{9}$. Esta realidade é historicamente contraditória, do mesmo modo que o é o processo de construção de políticas públicas visando à atenção odontológica integral em serviços públicos de saúde.

Desde a proclamação da República até 2004, os governos brasileiros, independentemente do regime, investiram em Odontologia pública setorial, priorizando exodontias para adultos e prevenção e tratamento para crianças em idade escolar ${ }^{9,10}$. As raízes da iniciativa estão no estilo de pensamento de vanguarda da época: cuidando dos dentes de crianças se terá adultos com dentes; para os adultos cujos dentes avançaram na história natural da cárie ou da doença periodontal, tem-se a exodontia.

Ainda na fase do Império, em 1880, começaram a ser instalados consultórios odontológicos em Santas Casas de Misericórdia, para fins de execução de exodontias ${ }^{10}$. Com a proclamação da República, em 1889, por meio de iniciativa decretada pelo estado de São Paulo ${ }^{11}$, o Brasil começava a difundir o modelo teórico higienismo escolar, de origem estadunidense ${ }^{12}$, que ancorou a implantação e expansão do Serviço Dentário Escolar ${ }^{12,13}$. A partir da Reforma Universitária de 1968, as universidades brasileiras passaram a adotar o modelo biomédico como ancoragem do processo de ensino-aprendizagem em saúde ${ }^{14}$. Este modelo não dá conta de transformar as desigualdades 
sociais em saúde em igualdade de direito ${ }^{9}$, uma vez que ao repartir o todo para estudar as partes o modelo promove um distanciamento dos acadêmicos da determinação social do processo saúde e doença: as pessoas e/ou as famílias adoecem (leia-se são acometidas por cárie e doença periodontal) em função do modo em que vivem e o modo de vida das pessoas e/ou famílias é determinado pela política macroeconômica do respectivo momento histórico de vida dessas pessoas e/ou famílias ${ }^{3}$.

Enfrentando tais projetos de exclusão social $^{9,10,15}$, o Programa Brasil Sorridente foi instituído em 2003, com a finalidade de garantir atenção odontológica comunitária integral no Programa Saúde da Família (PSF) ${ }^{16}$, editado no ano seguinte como Política Nacional de Saúde Bucal $^{17}$. Antes da conquista desta política, o que se tinha conquistado em termos de saúde coletiva em Odontologia eram incentivos financeiros para impulsionar a reorganização das práticas odontológicas no PSF, oportunizados por duas portarias: a Portaria n. 1.444 , de 28 de dezembro de $2000^{18}$ e a Portaria n. 673/GM, de 3 de junho de $2003^{19}$.

Com a Política Nacional de Saúde Bucal ${ }^{17}$, as práticas odontológicas passaram a reunir, a um só tempo, ações coletivas de promoção, manutenção e educação em saúde; ações coletivas de diagnóstico e de proteção específica a doenças bucais; ações individuais de diagnóstico e tratamento de doenças bucais (clínica de base); prevenção de agravos, e reabilitação, em conformidade com a vigilância em saúde e com planejamento orientado pela epidemiologia e informações do território. A vigilância em saúde é um dos pressupostos da reorientação do modelo de atenção, cuja atuação centra-se na avaliação e acompanhamento dos danos, riscos e determinantes do processo saúdedoença. Do mesmo modo, são pressupostos desta reorientação o uso da epidemiologia e de informações sobre o território, para oportunizar "que as ações sejam precedidas de um diagnóstico das condições de saúde-doença das populações, através da abordagem familiar e das relações que se estabelecem no território onde se desenvolve a prática de saúde".

Em 2006, a sociedade brasileira conquistou a Política Nacional de Atenção Básica (PNAB/2006), que conferiu à ESF a função de reorganizar as ações em nível de base. Sua implementação exige equipe multiprofissional composta por, no mínimo, médico (médico de família e comunidade, de preferência), enfermeiro (especialista em saúde da família, de preferência), auxiliar e/ou técnico de enfermagem e agentes comunitário de saúde. A ESF pode agregar equipe odontológica, composta por cirurgião-dentista (CD), de preferência, especialista em saúde da família, auxiliar e técnico em saúde bucal. Cada equipe de ESF é responsável por, no máximo, 4.000 pessoas do território adscrito e a jornada de trabalho para todos os profissionais é de $40 \mathrm{hs}$, inclusive dos profissionais de Odontologia, se existentes $^{20}$. A partir da PNAB/2006 municípios brasileiros começaram a investir na cobertura de práticas odontológicas, por meio da ESF.

Em 2008, o Departamento de Atenção Básica do Ministério da Saúde (DAB/MS) produziu o Caderno de Atenção Básica, no 17 , como referência para a reestruturação dos serviços odontológicos, em uma lógica integrada de processo de trabalho. Este documento descreve a necessidade de a Odontologia da AB "assumir uma nova postura diante da população [...] romper com antigas formas de trabalhar [...] conhecer o território em que [...] se trabalha compreendendo-o como um espaço social peculiar, historicamente construído, onde acontece a vida das pessoas e são estabelecidas as relações entre estas e destas com as diversas instituições existentes (culturais, religiosas, 
políticas, econômicas, entre outras)"21.

A conquista da PNAB e o lançamento do Caderno no 17 alavancaram a Política Nacional Brasil Sorridente, resultando na ampliação do acesso aos serviços especialmente de atenção básica, por meio da inserção de equipes de Odontologia na $\mathrm{ESF}^{22-24}$, bem como na ampliação e qualificação da atenção especializada, por meio da implantação de centros de especialidades odontológicas e laboratórios regionais em próteses dentárias, e da atenção de alta complexidade ${ }^{17}$.

As diretrizes da Política Nacional Brasil Sorridente recomendaram o modelo de cuidado, em contraposição ao assistencial, para deflagrar a atenção integral programática na atenção básica por meio de dois eixos: linhas do cuidado e condições de vida. O eixo linhas de cuidado segmenta a população de acordo com as características clínicas e/ou epidemiológicas específicas a cada população-alvo programática: grupo de 0-5 anos, grupo de crianças e adolescentes de 6 a 18 anos, grupo de gestantes, grupo de adultos e grupo de idosos. $\mathrm{O}$ eixo condições de vida prevê a abordagem da população a partir do seu universo familiar e das relações sociais experimentadas no território. Em ambos os eixos, a integralidade das ações de promoção de saúde, prevenção de doenças, educação em saúde, recuperação (diagnóstico e tratamento), redução de dados e riscos, urgência e emergência devem estar asseguradas ${ }^{17}$.

Quanto às ações de recuperação, as diretrizes da PNSB não fizeram menção ao agente regulador das ações programáticas da clínica e das ações de urgência e emergência, mas estudos empíricos demonstram que a regulação da clínica odontológica da atenção básica se dá pela noção de tratamento completado, herança do modelo incremental, instituído na segunda metade do século XX, e que as ações de urgência e emergência são reguladas pela noção de dor ${ }^{25}$.
A PNAB $/ 2006^{20}$ foi revisada e atualizada em $2011^{26}$ e também em $2017^{27}$. Nesta última atualização, a ESF foi mantida como estratégia prioritária, mas foram inseridas novas modalidades para a execução da $\mathrm{AB}$, de modo a flexibilizar a jornada de trabalho, tendendo, portanto, ao retorno da Odontologia assistencial.

Neste artigo, debate-se aspectos da realidade do processo de trabalho em saúde bucal e do empenho de cirurgiões-dentistas da ESF para garantir práticas odontológicas integrais individuais e coletivas aos respectivos territórios de atuação.

\section{METODOLOGIA}

Trata-se de uma pesquisa qualitativa, de nível exploratório-descritivo, desenvolvido em conformidade com a Resolução 466/12 e aprovado pelo Comitê de Ética da Universidade do Vale do Itajaí, por meio do CAAE 76943317.5.0000.0120, realizada entre maio de 2018 e fevereiro de 2019.

O município do estudo é de grande porte e, de acordo com a consulta realizada na página oficial da Secretaria Municipal de Saúde, em 19 de junho de 2018, conta com 52 (cinquenta e duas) equipes de Estratégia Saúde da Família e com 08 (oito) Equipes de Saúde Bucal (ESB), compostas por dentista, auxiliar e técnico de saúde bucal.

O primeiro movimento metodológico foi apresentar a pesquisa ao Coordenador de Saúde Bucal do município, e solicitar os endereços das 08 (oito) Unidades Básicas de Saúde (UBS) com ESF e equipes de Saúde Bucal, bem como os nomes dos cirurgiões-dentistas.

De posse dessas informações, elaborou-se uma carta convite para cada profissional. No primeiro dia de exploração dos territórios, foram visitadas quatro UBS. Os CD da ESF foram convidados e aceitaram participar do estudo. Datas e horários foram agendados. 
Noutro momento, em visita à UBS mais afastada do centro do município, soube-se que o cirurgião-dentista da ESF local não tinha mais vínculo com a Rede Básica. Em seguida, visitouse as três últimas UBS, indicadas pelo coordenador. Os $\mathrm{CD}$ preferiram não agendar data e horário para a coleta, mas fornecer os números de seus celulares para um agendamento futuro, de acordo com suas agendas de trabalho. Dali em diante, iniciou-se a coleta de dados.

Quatro entrevistas foram realizadas sem intercorrências, sendo que três aconteceram em espaços das UBS e uma em outro local, sugerido pelo(a) participante.

Duas entrevistas, entretanto, tiveram que ser remarcadas, pois os profissionais não estavam presentes na data e horário agendados. No primeiro caso, soube-se que o motivo foi atraso na vinda para a UBS devido ao trânsito. Fez-se um novo agendamento, mas novamente houve um imprevisto com o profissional. Em um terceiro momento, a entrevista foi agendada via WhatsApp e realizada. No segundo caso, a remarcação da entrevista foi necessária em virtude de o(a) cirurgião-dentista estar de atestado. $\mathrm{O}$ encontro foi reagendado, mas o profissional não estava presente. Um terceiro agendamento foi feito e a entrevista foi executada.

Ao final, seis profissionais participaram do estudo. A sétima entrevista não aconteceu porque o(a) profissional decidiu não participar no momento da coleta, justificando por meio de uma terceira pessoa da equipe que estava ocupado(a) com os atendimentos e que outros profissionais da ESF poderiam colaborar com a pesquisa.

Uma vez concluída a coleta de dados, o material gravado em áudio, totalizando 4 horas e 10 minutos, foi transcrito e organizado.

A análise dos dados foi realizada por meio de análise temática adaptada. $\mathrm{O}$ ajustamento da técnica foi necessário, em virtude de o estudo não ter previsto a investigação da frequência das mensagens expressas em palavras, expressões e/ou frases, mas a significância de argumentos e ideias apreendidos, independentemente do número de vezes em que se fizeram manifestar ${ }^{28}$.

$\mathrm{O}$ processo de análise foi realizado por meio de seis etapas ${ }^{28}$ :

- Relação preliminar com o material: os acadêmicos certificaram-se que o conteúdo bruto era pertinente para responder o objetivo geral e tinha representatividade;

○ Contaminação pelo material: obtida por meio de várias leituras, desprovidas de análise e/ou interpretação;

- Seleção das unidades de registro (unidades com significância: palavras, expressões e/ou frases) e de contexto (extratos mais amplos, nos quais estão as unidades de registro);

- Codificação e agrupamento de códigos: atribuição de códigos às unidades de registro, com base em critério semântico, e agrupamento dos códigos por analogia;

- Exploração transversal do material: afastamento da codificação e retomada do material bruto visando à leitura transversal para verificar se, porventura, alguma pergunta havia sido elucidada em conjunto com outra resposta; e

- Categorização: em um esforço de abstração, procedeu-se à categorização.

Foram geradas três categorias de análise: "Diretrizes sociais e clínicas das práticas odontológicas na ESF"; "Por uma Odontologia comunitária: fronteiras em debate"; e "Por uma Odontologia comunitária: aspectos da realidade e de esforços de cirurgiões-dentistas em debate". Neste artigo, será discutida a terceira categoria.

\section{RESULTADOS E DISCUSSÃO}

Com base na categoria "Por uma 
Odontologia comunitária: aspectos da realidade e de esforços de cirurgiões-dentistas em debate", os resultados serão apresentados e discutidos em interlocução com o referencial teórico, vivências, concepções de mundo e de práticas odontológicas na ESF.

Ao serem convidados para compartilhar aspectos da experiência profissional, com o objetivo de localizar elementos do processo de trabalho vivido na ESF, cirurgiões-dentistas revelaram um empenho robusto em se apropriar da filosofia prática e/ou expandi-la: [...] eu tive que aprender a fazer ESF [...] com a ESF você aprende um pouco mais de você mesmo, sobre suas capacidades [...] e [Ela] me ensinou o alcance social (E3) Sobre a minha experiência é conseguir ativar os pilares da Estratégia [...] a gente primeiro precisa ouvir a comunidade para saber o que ela quer [...] [...] antes de ser dentista eu sou agente de saúde (E5) [...] eu caí de paraquedas porque no concurso não é pedido nada específico [...] quando eu saí da faculdade não se falava em saúde bucal [...] eu tive que correr atrás de especialização em saúde da família e descobri que eu era estratégia [...] era tudo que eu gostava de fazer (E6) [...] eu olhei muito no edital do concurso pra saber o que eu tinha que fazer e em manuais que me deram (E2).

Os depoimentos revelam que, ao contrário do imaginário historicamente construído no Brasil, a atuação em Odontologia pública de base não é simples, mas complexa por requerer a desconstrução da prática procedimental individualizada. Eles sinalizam o reconhecimento de que é preciso disposição para apreender a dimensão pública fazendo apreendê-la no fazer - e que a graduação nem sempre é suficiente para garantir a apropriação das diferentes clínicas de base e de ações coletivas necessárias ao território. As falas traduzem, ainda, cirurgiões-dentistas despojados de preceitos da Odontologia individualizada tradicional, ao demonstrarem um esforço substantivo de transformação do intelectual dentista em um intelectual criativo e orgânico, que assume para si e para o outro que tem/teve que reaprender o ofício no ato de fazê-lo, em outra lógica. Em uma lógica [...] ativa [...] com potência para nela se descobrir ESF e descobrir que [...] era tudo que eu gostava de fazer; em que se aprende [...] um pouco mais de você mesmo, em cujos [...] pilares [...] está o sujeito das ações chamado comunidade. Uma lógica a partir do Brasil real, diferente daquela autorizada pelo saber predominante da graduação que informa ao cliente o tratamento que deve ser feito, já que na ESF as diferentes clínicas de base não são meramente procedimentos, mas práticas sociais.

Um estudo de caso, publicado em 2015, e desenvolvido com vinte e quatro (24) municípios de uma regional de saúde do interior paulista analisou os fatores organizacionais e relacionais implicados no processo de implantação do Brasil Sorridente. A interpretação dos fatores identificados enfatiza que "é preciso pensar mudanças nos modelos assistenciais [...] ressignificar os modos de se produzir cuidado em saúde bucal, as relações profissionais-usuários $[\ldots]^{\prime 29}$.

Uma forma de mudança é apresentada pelos depoimentos supracitados: um vir a ser na prática, tornando-se criativo e orgânico, no espaço de atuação. Para tanto, há duas questões históricas de fundo a serem discutidas: a primeira, diz respeito ao custo alto sofrido pelas diferentes clínicas de base da Odontologia em razão da necessidade de imprimir uma lógica de atenção na ESF, em conformidade com "a diretriz da integralidade" $" 30$.

Para construir a atenção integral a indivíduos, famílias e comunidades, arquitetos e grande parte de executores do Brasil Sorridente e docentes de Saúde Coletiva vêm focando, desde a criação do PSF, em fundamentos coletivos 
como humanização, acolhimento, vínculo, responsabilização, trabalho em equipe, intersetorialidade, interdisciplinaridade, resolutividade, impulsão à autonomia das pessoas e à participação no controle social $^{16,20,21,26,27}$. Esse movimento, quase que exaustivo, gerado pela necessidade de pavimentação humanística para práticas odontológicas integrais acabou marginalizando a qualificação e regulação das clínicas de base provavelmente por darem-na como óbvia na formação em Odontologia, quando o que se percebe na fala de E6 é eu tive que correr atrás de especialização em saúde da família. Ou seja, para que as práticas clínicas odontológicas da ESF traduzam a construção de uma Odontologia pública de base que se faça, a um só tempo, de excelência clínica e integral comunitária, é preciso recorrer a uma pós-graduação.

Pesquisa bibliográfica realizada sobre as mudanças ocorridas nas práticas odontológicas, a partir da conquista da política nacional, revelou que o novo cenário normativo não resultou em mudanças estruturais no processo de trabalho. Os autores questionam a compreensão incipiente sobre a dinâmica do trabalho em Odontologia na $\mathrm{AB}$ e o pouco avanço na qualificação da atenção, e sugerem o repensar das práticas tradicionais $\mathrm{e}$ um modo inovado de se fazer saúde bucal ${ }^{31}$.

A segunda questão de fundo a ser discutida diz respeito ao uso da expressão "Saúde Bucal" no arcabouço da ESF para designar práticas individuais, familiares e comunitárias.

$\mathrm{Na}$ perspectiva dos autores deste manuscrito, são os momentos históricos que condicionam o modo como uma dada prática é instituída e um dado modelo teórico e/ou conceito é pensado. Em 2004, por exemplo, houve condições de possibilidades para o Brasil gestar a feliz expressão "Brasil Sorridente" em contraposição a um Brasil sem dentes. No entanto, ao oficializar a expressão "Saúde
Bucal", para sustentar a Política Nacional, o Brasil não parece ter feito uma escolha feliz.

Em que pese o considerável avanço oportunizado pela criação do campo "Saúde Bucal Coletiva" (SBC), nos anos 80, como forma de superação à Odontologia Sanitária, Odontologia Simplificada e Odontologia Preventiva e Social, e de sensibilização a práticas comunitárias, o fato é que a própria $\mathrm{SBC}$ ainda não encontrou condições para alargar o espaço de luta e impulsionar o tão caro movimento contra hegemônico para "reverter a direção das práticas odontológicas em curso" 32 .

A expressão Saúde Bucal pode ser coerente para fundamentar a prevenção e o tratamento de doenças bucais em práticas assistenciais de atenção básica, garantidas por jornadas de trabalho de 15 horas, pois, nesses casos, o foco é a prevenção individual e a doença pontual demandadas por usuários. No entanto, a expressão não é adequada para ancorar a ESF, executada por jornadas de trabalho de $40 \mathrm{hs}$ para responder por práticas abrangentes de cunho técnico, filosófico e político. O reducionismo produzido pela adjetivação de Saúde (Bucal) limita a necessária ousadia para se pensar em ações transformadoras da realidade, no sentido de a comunidade reconhecer que seu direito de envelhecer com dentes é uma questão política, está para além de um tratamento pontual. Limita, ainda, práticas sociais coletivas de promoção de saúde; práticas emancipatórias de educação em saúde e de participação social na fiscalização da Política Nacional. Nesta linha compreensiva, é fundamental refletir sobre a contradição que se imprime quando não se defende a dimensão filosófica e política de saúde, tampouco saúde e doença como fenômenos distintos mutuamente complementares $^{3}$, no âmbito do arcabouço do Brasil Sorridente e da ESF.

Explorando as práticas odontológicas desenvolvidas no exercício da ESF, obteve-se os 
seguintes relatos: [...] basicamente a gente faz assim: a gente divide entre clinica e atividade coletiva: escola, creche, grupos, reunião de equipe [...] mais ou menos $70 \%$ da carga horária para cuidar da clínica [...] (E1) [...] todas as clínicas gerais eu faço [...] periodontia, cirurgia, dentística, endodontia, odontopediatria, necessidades especiais, acompanho gestantes, faço pré-natal odontológico [...] depois tem escolha, creches e visita domiciliar [...] fico mais tempo no mocho [...] a demanda clínica é muito maior do que ações coletivas (E2) [...] a gente faz visitas domiciliares [...] trabalho de prevenção nas escolas e [...] atendimento clínico. Os procedimentos clínicos são basicamente restaurações, selamentos provisórios, acesso coronário para encaminhamento de tratamento de canal, exodontias não muito difíceis, radiografias, raspagens supragengivais $e$ encaminhamento pra lesões. [...] Basicamente é isso. (E4)

A primeira observação, gerada na relação com esses dados, foi sobre o papel que o advérbio "basicamente" exerce sobre os verbos fazer e ser. Refletindo sobre as unidades de contexto que expõem o termo, percebe-se que seu uso foi um recurso para evitar um relato pormenorizado, isto é, os profissionais que usaram o advérbio o fizeram para anunciar brevemente o que pensam sobre a pergunta, encerrando pragmaticamente a reflexão. Aproximando essa percepção da histórica escolha de substituir a expressão Atenção Primária à Saúde por Atenção Básica, em função de um dos sentidos da tradução de primary care, no Brasil, representar atenção seletiva $^{33}$, observa-se que nem sempre a fuga semântica consegue evitar o que não é bemvindo. Pois, a expressão Atenção Básica ainda não foi capaz de se fazer robusta, de parametrizar com "reflexividade dirigida"1 o que propõe.

A segunda observação é sobre a generalidade com que as práticas individuais e coletivos realizadas são expressas: [...] faço clínica e atividade coletiva: escola, creche, grupos, reunião de equipe [...] (E1) [...] todas as clínicas [...] periodontia, cirurgia, dentística, endodontia, odontopediatria, necessidades especiais, acompanho gestantes, [...] pré-natal odontológico (E2) [faço] visitas domiciliares [...] prevenção nas escolas [...] restaurações, selamentos provisórios, acesso coronário para encaminhamento de tratamento de canal, exodontias não muito dificeis, radiografias, raspagens supra gengival e encaminhamento pra lesões (E5). As falas denotam ausência de parâmetros, para as distintas clínicas de base, alinhados a cada território de ESF. Não referem uma programação estrutural comum, com respeito evidentemente às peculiaridades locais.

Este nó crítico tem uma de suas raízes no modo como se deu a programação das práticas pelo ordenamento da esfera federal: não saber aonde se quer chegar com a dita atenção integral em saúde bucal, enquanto Unidade federativa. A Política Nacional de Saúde Bucal não apresentou um marco regulatório para as ações programáticas nem as linhas de base operativas que estariam conduzindo as práticas odontológicas integrais na $\mathrm{ESF}^{16}$. A condução nacional das políticas públicas nacionais é conhecida. A União formula as políticas, programas e diretrizes, e concede incentivos financeiros ${ }^{34}$. O estado formula a sua política, seus programas e diretrizes, à luz das formulações da União e repassa algumas verbas aos municípios ${ }^{35}$. Os Municípios executam o que foi formulado ${ }^{34}$, por meio de planos municipais de saúde e controle social, e respondem pela maior parte do orçamento do setor. E a pergunta aonde se quer chegar, considerando os princípios de universalidade e igualdade, fica à espera de respostas.

Outro empenho manifestado por cirurgiões-dentistas foi com relação à 
engenharia, para dar conta de cuidar de territórios em franca expansão populacional, sem a inclusão de mais equipes de Saúde Bucal na ESF. Em função dessa expansão, alguns profissionais têm optado por limitar o cuidado à uma área do território, deixando as demais descobertas do cuidado integral, ainda que coberta por atividades coletivas importantes como puericultura e pré-natal odontológico. Cabe assinalar que o município tem uma ampla rede básica em assistência odontológica, formada por profissionais ambulatoriais com jornada semanal de 15 horas. No entanto, atendimento clínico pontual está longe de ser cuidado integral.

De acordo com o Caderno de Atenção Básica, $n^{\circ}$ 17, as Secretarias Municipais de Saúde devem estabelecer parâmetros de orientação, acompanhamento e avaliação do processo de trabalho das equipes e metas para a garantia do cuidado, tanto por ciclo de vida como por condições de vida, delineadas após o conhecimento da realidade sociocultural e epidemiológica da população, "tomando por base os recursos existentes para enfrentamento dos problemas, um número mínimo de procedimentos e consultas deve ser seguido" 21 .

E, aqui, perguntas são geradas: para programar as práticas odontológicas de um território deve-se tomar por base recursos existentes e rol mínimo de procedimentos ${ }^{20} \mathrm{ou}$ necessidades de saúde, emergentes e acumuladas por um débito histórico avassalador? O que significa realidade sociocultural senão a realidade socialmente construída, em processo, por homens, mulheres, crianças, adolescentes, adultos e idosos de um dado território, de acordo com suas condições de vida e relações estabelecidas? Relatos evidenciam a realidade: Um consultório para uma área de $10 \mathrm{mil}$ habitantes é humanamente, fisicamente impossível (E5) [...] hoje eu já me limito mais à minha área, comecei a não dar conta mais, muita coisa [...] (E1) [...] meu público é de mais ou menos 8 mil pessoas [...] (E2) a gente precisa de muito mais equipes, muito mais [...] (E3)

Outro aspecto da realidade, apresentado por um cirurgião-dentista como correlato aos entraves do desenvolvimento das práticas odontológicas na ESF, foi [...] a odontologia hoje não tem muita representação política [...] a equipe de saúde bucal não é considerada tão importante [...] (E4). Essa fala pode ser discutida em nível setorial e macro.

No plano setorial, é fato que desde a PNAB/2006 a inclusão da Odontologia na ESF está condicionada à vontade de prefeitos. O próprio texto do documento é muito claro: a ESF "pode agregar" equipes de saúde bucal, sendo a inclusão estimulada por incentivos federais e executada de modo indutivo. Em não sendo possível, a Odontologia assistencial pode substituir as equipes de saúde bucal.

Ainda em nível setorial, o movimento da Saúde Bucal Coletiva parece viver um arrefecimento em sua luta por práticas sociais em Odontologia. Estudo nacional realizado em 2017 buscou, nas vozes dos agentes fundadores e precursores da Saúde Bucal Coletiva, a compreensão sobre a permanência das "Odontologias Alternativas" no campo social de luta pela saúde bucal. Os autores sinalizaram que permanecem vigentes as "antigas 'Odontologias' na produção científica e nas práticas”, embora a Saúde Bucal Coletiva valorize a dimensão crítica $^{32}$.

No plano macro, a possibilidade de inserção de equipes de saúde bucal na ESF fezse presente ao mesmo tempo em que houve o fortalecimento da Odontologia liberal-privatista, conformando mercados ativos no setor, "que disputam os recursos do Estado e das famílias"36. Ademais, vale citar a ampliação das especialidades odontológicas e estéticas em Odontologia, resultante da valorização 
exacerbada do culto à estética e desenvolvimento tecnológico para este fim $^{37}$.

Obviamente o tema não se esgota aqui. Deixa-se, entretanto, uma provocação: seria razoável refletir sobre o potencial da expressão "Odontologia comunitária" na luta por uma Odontologia de base territorial, de cunho não somente técnico, mas, também, filosófico e político.

Como limite deste artigo, considera-se o fato de a pesquisa ter sido realizada por uma única força de trabalho da cadeia produtiva de práticas odontológicas na ESF. Novos estudos, inserindo outros trabalhadores são oportunos.

\section{CONCLUSÃO}

Foram identificadas iniciativas importantes para garantir as práticas sociais pertinentes à ESF. No entanto, a realidade expõe o risco de as práticas odontológicas desviarem-se de sua filosofia, uma vez que as poucas equipes de Saúde Bucal existentes estão assumindo contingentes populacionais para além de sua capacidade de atuação, e sem programação territorial que parta de um planejamento efetivo que considere aonde se quer chegar.

\section{ABSTRACT \\ Reality and efforts of dental surgeons in community Dentistry}

This article concerns to the context of the Family Health Strategy of a large city in the state of Santa Catarina, Brazil, in order to discuss aspects of the reality of the oral health work process and the commitment of dental surgeons to ensure comprehensive individual and collective dental practices. It is a qualitative, exploratorydescriptive study, carried out with six dental surgeons through semi-structured interviews and adjusted thematic analysis. The results indicate a mismatch between the number of oral health teams, per registered population, absence of regulatory parameters and goals for the different dental-based clinics, and absence of structural alignment between the practices developed and the sociocultural reality of each territory. A great effort was identified by the collective of professionals in order to: a) take ownership of the Family Health Strategy (FHS) philosophy on a daily basis and/or expand it; b) recognize that is necessary to be willing to learn the public dimension of oral health in the act of doing it, because undergraduation is not always enough to ensure the appropriation of individual and collective oral health clinics; c) recognize the importance of becoming a creative and organic intellectual, who takes on a social rule; and d) overcome the effects generated in the practices due to the lack of political representation of the Family Health Strategy oral health. The guarantee of comprehensive dental practices is considered to be on the horizon, waiting for conditions of possibilities to make real what is still in the plan of autonomous efforts, of the institutional framework and of good intentions.

Descriptors: Community Dentistry. Family Health Strategy. Primary Health Care.

\section{REFERÊNCIAS}

1. Cruz TO, Lima RCGS. Percepções de especialistas em Cirurgia e Traumatologia Buco-Maxilo-Faciais sobre as motivações da escolha e a atuação profissional. Revista da ABENO. 2019; 19(4):22-33.

2. Werneck MAF, Senna MIB, Drumond MM, Lucas SD. Nem tudo é estágio: contribuições para o debate. Ciênc Saúde Colet. 2010; 15 (1):221-31.

3. Da Ros MA, Lima RCGS, Maximo CE. Fundamentos da promoção da saúde requerida pelo SUS. In: Farhat E, Dittrich MG, organizadores. Educação em Saúde: Políticas Públicas e Vivências Dialógicas. Itajaí: UNIVALI; 2016. p. 97-115. 
4. Universidade Federal do Rio Grande. Curso de Medicina. Projeto Pedagógico do Curso. [Acesso em 23 mar. 2019]. Disponível em: https://medicina.furg.br/images/Normas_Ac ademicas/PROJETO_PEDAGGICO_CURS O_MEDICINA.pdf.

5. Universidade Federal do Oeste do Pará. Projeto Pedagógico do Curso de Bacharelado em Saúde Coletiva. 2018. [Acesso em 23 mar. 2019]. Disponível em: http://www.ufopa.edu.br/media/file/site/ufo pa/documentos/2018/7d4c0250c66bccb581 e0096c3f360c84.pdf.

6. Fundação Universidade Federal do Tocantins. Curso de Medicina. Projeto Pedagógico do Curso. 2008. [Acesso em 23 mar. 2019]. Disponível em: https://docs.uft.edu.br/share/proxy/alfrescon oauth/api/internal/shared/node/okWN9dpeS h6z8K3NlwE_kw/content/ppc_medicina_n ov_2008_2187.pdf.

7. Almeida Filho NM de. Contextos, impasses e desafios na formação de trabalhadores em Saúde Coletiva no Brasil. Ciênc Saúde Colet. 2013; 18(6):1677-82.

8. Costa HOG, Rangel ML. Desafios do Ensino da Saúde Coletiva na Graduação dos Profissionais de Saúde. Ciênc Saúde Colet. 1997; 2(1-2):164-71.

9. Lima RCGS. Reconhecendo o desafio latente na história: periodização contextualizada dos modelos de saúde bucal. Saúde Transform Soc. 2017; 8 (2):15-25.

10. Silvestre JAC, Aguiar ASW de, Teixeira EH. Do Brasil sem Dentes ao Brasil Sorridente. Cadernos ESP. 2013;7(2):28-39.

11. São Paulo. Assembleia Legislativa do Estado de São Paulo. Decreto n. 4.600, de 30 de maio de 1929. Regulamenta as leis 2.269, de 31 de dezembro de 1927 , e 2.315 , de 31 de dezembro de 1928, que reformaram a Instrucção Publica do Estado. [Acesso em 23 mar. 2019]. Disponível em: https://www. al.sp.gov.br/repositorio/legislacao/decreto/1 929/decreto-4600-30.05.1929.html.

12. Brasil. Ministério da Saúde. Desenvolvimento de sistemas e serviços de saúde. Brasília: MS; 2006. [Acesso em 23 mar. 2019]. Disponível em: http://bvsms. saude.gov.br/bvs/publicacoes/regulacao_set or_saude_americas.pdf.

13. Narvai PC, Frazão C. Políticas de Saúde Bucal no Brasil. In: Moysés TS, Kriger L, Moysés SJ, organizadores. Saúde Bucal das famílias: trabalhando com evidências. São Paulo: Artes Médicas; 2008. p. 1-20.

14. Mendes EV. Uma agenda para a saúde. São Paulo: Editora Hucitec; 1996.

15. Junqueira SR, Frias AC, Zilbovicius C. Saúde bucal coletiva: quadros social, epidemiológico e político. In: Rode SM, Nunes SG, organizadores. Atualização clínica em odontologia. São Paulo: Artes Médicas; 2004. p. 591-604.

16. Brasil. Ministério da Saúde. Secretaria de Atenção à Saúde. Departamento de Atenção Básica. Memórias da Saúde da Família no Brasil. Brasília: MS; 2010. [Acesso em 23 jun. 2019]. Disponível em: http://bvsms. saude.gov.br/bvs/publicacoes/memorias_sa ude familia brasil.pdf.

17. Brasil. Coordenação Nacional de Saúde Bucal. Departamento de Atenção Básica. Secretaria de Atenção à Saúde. Ministério da Saúde. Diretrizes da Política Nacional de Saúde Bucal. 2004. [Acesso em 23 mar. 2019]. Disponível em: http://189.28. 128.100/dab/docs/publicacoes/geral/diretriz es_da_politica nacional_de_saude bucal.p df.

18. Brasil. Ministério da Saúde. Portaria n. 1.444, de 28 de dezembro de 2000. Estabelece incentivo financeiro para a reorganização da atenção à saúde bucal 
prestada nos municípios por meio do Programa de Saúde da Família. Brasília: MS; 2000. [Acesso em 23 jun. 2019]. Disponível em: https://www.camara.leg.br/ proposicoesWeb/prop_mostrarintegra;jsessi onid=2855A1BDAAD7DEF4C17F7A7373 C9E8D8.node1?codteor $=142359 \&$ filename =LegislacaoCitada+-PL+1274/2003.

19. Brasil. Ministério da Saúde. Portaria n. 673/GM, de 3 de junho de 2003. Atualiza e revê o incentivo financeiro às Ações de Saúde Bucal, no âmbito do Programa de Saúde da Família, parte integrante do Piso de Atenção Básica. Brasília: MS; 2003. [Acesso em 23 jun. 2019]. Disponível em: http://bvsms.saude.gov.br/bvs/saudelegis/g m/2003/prt0673_03_06_2003.html.

20. Brasil. Portaria 648/GM/2006, de 28 de março de 2006. Aprova a Política Nacional de Atenção Básica, estabelecendo a revisão de diretrizes e normas para a organização da Atenção Básica para o Programa Saúde da Família (PSF) e Programa Agentes Comunitários de Saúde (PACS). Brasília: MS; 2006. [Acesso em 23 mar. 2019]. Disponível em: http://dab.saude.gov.br/ docs/legislacao/portaria_648_28_03_2006. pdf.

21. Brasil. Ministério da Saúde. Saúde bucal. Brasília: MS; 2006. (Cadernos de Atenção Básica, n. 17) (Série A. Normas e Manuais Técnicos).

22. Pucca Junior G. A política nacional de saúde bucal como demanda social. Ciênc Saúde Colet. 2006; 11: 243-6.

23. Baldani MH, Fadel CD, Passamai T, Queiroz MGS. A inclusão da odontologia no Programa Saúde da Família no Estado do Paraná, Brasil. Cad Saúde Pública. 2005; 21(4): 1026-35.

24. Pereira CRS, Patricio AAR, Araújo FAC, Lucena EES, Lima KC, Roncalli AG.
Impacto da Estratégia Saúde da Família com equipe de saúde bucal sobre a utilização de serviços odontológicos. Cad Saúde Pública. 2009; 25: 985-96.

25. Bulgareli J, Cortellazi KL, Ambrosano GMB, Meneghim MC, Faria ET, Mialhe FL et al. A resolutividade em saúde bucal na atenção básica como instrumento para avaliação dos modelos de atenção. Ciênc Saúde Colet. 2014; 19 (2): 383-391.

26. Brasil. Portaria n. 2488 de 21 de outubro de 2011. Aprova a Política Nacional de Atenção Básica, estabelecendo a revisão de diretrizes e normas para a organização da atenção básica, para a Estratégia Saúde da Família (ESF) e o Programa de Agentes Comunitários de Saúde (PACS). Brasília: MS; 2011. [Acesso em 23 mar. 2019]. Disponível em: http://bvsms.saude.gov.br/ bvs/saudelegis/gm/2011/prt2488_21_10_20 11.html.

27. Brasil. Ministério da Saúde. Portaria n. 2436/GM/MS, de 21 de setembro de 2017. Aprova a Política Nacional de Atenção Básica, estabelecendo a revisão de diretrizes para a organização da Atenção Básica, no âmbito do Sistema Único de Saúde (SUS). Brasília: MS; 2017. [Acesso em 23 mar. 2019]. Disponível em: http://bvsms.saude. gov.br/bvs/saudelegis/gm/2017/MatrizesCo nsolidacao/comum/250584.html.

28. Minayo MCS. O desafio do conhecimento. Pesquisa qualitativa em saúde. 14 ed. São Paulo: Hucitec; 2014.

29. Aquilante A, Aciole GG. Construindo um "Brasil Sorridente"? Olhares sobre a implementação da Política Nacional de Saúde Bucal numa região de saúde do interior paulista. Cad Saúde Pública. 2015; 31 (1): 82-96.

30. Luciana Jaccoud L, Vieira FS. Federalismo, Integralidade e Autonomia no SUS: 
desvinculação da aplicação de recursos federais e os desafios da coordenação. Texto para discussão / Instituto de Pesquisa Econômica Aplicada. Brasília: Rio de Janeiro; 2018. [Acesso em 23 jun. 2019]. Disponível em: http://repositorio.ipea.gov. br/bitstream/11058/8523/1/TD_2399.pdf.

31. Scherer CI, Scherer MDA. Avanços e desafios da saúde bucal após uma década de Programa Brasil Sorridente. Rev Saúde Pública. 2015; 49(98): 1-12.

32. Soares CLM, Paim JS, Chaves SCL, Rossi TRA, Barros SG, Cruz DN. O movimento da Saúde Bucal Coletiva no Brasil. Ciênc Saúde Colet. 2017; 22 (6):1805-16.

33. Giovanella, L. Atenção básica ou atenção primária à saúde? Cad Saúde Pública. 2018; 34 (8): e00029818.

34. Arretche M. Democracia, federalismo e centralização no Brasil. Rio de Janeiro: Fiocruz; FGV; 2012.

35. Brasil. Administração Pública. União, estados e municípios têm papéis diferentes na gestão do SUS. 2014. [Acesso em 23 mar. 2019]. Disponível em: http://www. brasil.gov.br/governo/2014/10/o-papel-decada-ente-da-federacao-na-gestao-da-saudepublica.
36. Machado CV, Lima LD, Baptista TWF. Políticas de saúde no Brasil em tempos contraditórios: caminhos e tropeços na construção de um sistema universal. Cad Saúde Pública 2017; 33 Sup 2: e00129616.

37. Tesser CD, Pezzato LM, Silva EM. Medicalização social e odontologia: possíveis aproximações. Saúde Soc. 2015; 24(4): 1349-61.

\section{Correspondência para:}

Rita de Cássia Gabrielli Souza Lima

e-mail: rita.lima@univali.br

Rua Uruguai, 458 - Bloco F6 - Sala 311

88302202 Itajaí/SC 